\title{
Towards better understanding electronic music festivals motivation
}

\author{
Danijela Ferjanić Hodak* \\ Goran Belošević ** \\ Antonio Vlahov*
}

Abstract: Electronic music festivals became one of the most successful forms of tourism for young adults. In the paper, authors aimed to explored the motivation and the perception of the potential visitors of electronic music festivals in Croatia and to identify the key dimensions of electronic music festivals. Instrument used for the primary research was a structured on-line questionnaire distributed among students of the University of Zagreb. In total, 350 questionnaires were collected and analyzed. Factor analyses resulted with three factors concerning motivation (music and fun, travel, socialization). Motives with the highest mean value are closely related with the core of electronic music festival offer, but other motives should not be neglected. Paper provides several recommendations for the improvement of electronic music festival offer and suggest the direction and possibilities for the future research.

Keywords: event tourism; electronic music; electronic music festivals; motivation

JEL Classification: L83, G14, L82

\section{Introduction}

Since ancient times, different kind of events attract people to take part which results with the unique experience and personal satisfaction. Event participation generally includes leisure travel which can be attributed to tourism. Nowadays, events have become a core element of a destination system which influences destination attractiveness and global competitiveness, but also attracts visitor spending (Getz, 2016: 593).

\footnotetext{
* Danijela Ferjanić Hodak and Antonio Vlahov are at Faculty of Economics and Business, University of Zagreb, Zagreb, Croatia.

** Goran Belošević is at Gold Entertainment Management Agency.
} 
Creating an extra offer by having an event obtains many positive effects for the destination, such as "creation of the positive image of a destination and bringing money into the local economy" (Kruger and Saayman, 2019: 2399). Destinations are also motivated to host different kind of events due to the fact that this will: "attract tourists (especially in the off-peak seasons), improve the infrastructure and tourism capacity of the destination, foster a positive destination image and contribute to general place marketing (including contributions to fostering a better place in which to live, work and invest), and to animate specific attractions or areas" (Getz, 2008: 405,406). Furthermore, as Derrett (2009: 108) stated "events feed into the image and identity of the community and assist with creating an appealing and consolidated sense of the community". According to same author, one of the main advantages of hosting the events is the fact that the majority of them (especially when it comes to music festivals) does not require a lot of infrastructure, which depends on the type of event. Events can be classified by different criteria, but the most commonly used are the size and the topic (or the theme) of the event. Different authors provide different classification, but the majority of them assorts events in seven main theme-based groups: sport events, cultural events, entertainment events, religious events, economic events, scientific events and political events.

Music festivals, which are in the scope of this paper, can be characterized both as cultural and entertainment events. According to Frey, "music festivals date from 11th century (French troubadours took part in the festivities of the guilds), and the oldest contemporary music festival is the Three Choirs Festival in Glucester, Hereford and Worcester, which dates back to 18th century, followed by the Handel Festivals in Westminster Abbey" (1994: 29). Since then, music has changed in large scale, but the interest of the demand for attending music festivals is constantly growing. Due to increase in the demand, the number of music festivals and the destinations offering this kind of entertainment is also in constant growth, especially the one based on electronic music, which has diverse and numerous audience around the world, and represent a great potential for tourism destinations. Electronic music can be defined as "a music based on the usage of technologically produced sound, including synthesizers and computer audio production programs" (Kruger and Saayman, 2019; St John, 2006). Despite the fact that it has arrived in the UK around 1970s (Kruger and Saayman, 2019: 219), it became globally popular in the new millennium. It includes many different sub-genres like house, trance, techno, etc. Research taken by Caparrini et al. (2020) showed that more than 20 subgenres can be defined at this moment, and new subgenres evolve rapidly, due to the fact that thousands of new songs are released every week.

A large number of city officials and organizers of the events, as well as the researchers, are becoming more aware of the fact that community cohesion and impacts of the events (both economic and noneconomic), as well as the different motivation for the attendance of events, are all interconnected (Yolal, Çetinel, and Uysal, 2009). Therefore, when it comes to electronic music festivals, there are three main pillars 
in the focus of theory and practice: motivation, involvement of the local community and impacts.

The aim of the paper is twofold. Firstly, authors wanted to explore the motivation and the perception of the potential visitors of electronic music festivals in Croatia. Secondly, they wanted to identify the key dimensions of electronic music festivals, which includes not only the content and infrastructure primarily related with the music festivals, but also the dimensions within the destination, such as accommodation, attractions, etc. Beside the scientific contribution, the paper provides an information for the stakeholders in the destinations involved in event tourism.

\section{Theoretical background}

Special interest tourism is one of the fastest growing segments within the tourism industry (Douglas, Douglas and Derett, 2002). Term „special interest tourism“ (SIT) emerged in 1980s (Weiler and Hall, 1992) as a counterbalance to mainstream tourism. Tourists became more experienced and have developed a higher level of expertise (Novelli, 2005). Due to this fact, market had to adopt to the expectations of tourism demand by creation of SIT offer. This phenomenon represents a slew in tourism supply; standardized and rigidly packaged supply becomes more specialised and unique (Agarwal, Busby and Huang, 2018). The main aim of SIT is to satisfy specific need of tourism demand based on specific motivation for travel. Therefore, tourism destination has to adapt offer in order to provide specific service which can fulfil the expectation of tourists. SIT can be divided into two main groups, depending on basic resources needed for its development. First group involves SIT based mostly on natural resources (e.g. health tourism, nautical tourism, eco-tourism, etc.), while second group involves SIT based mostly on social (man-made) resources (e.g. M.I.C.E. tourism, cultural tourism, event tourism).

Event tourism, an important and rapidly growing segment of international tourism (Getz, 2016; Getz, 1989), can be defined as a special interest tourism type which includes all travel motivated by active or passive participation on any kind of special event. Special event is considered as a "phenomenon arising from those non-routine occasions which have leisure, cultural, personal or organizational objectives set apart from the normal activity of daily life" (Shone and Parry, 2013: 6,7). Although SIT forms should be based on small scale and minimize the negative effects on the destination, special events can attract a large number of people in the destination at the same time, and therefore have to be well planned and managed in order to avoid as many negative effects as possible. Event tourism involves a broad industry framework affecting the social, political, environmental and economic context of the tourism region and tourist market (Douglas, Douglas and Derett, 2002). On the other hand, significant and constant growth of the event industry worldwide has created 
opportunities for management professionals in a wide variety of settings (Robinson, Wale and Dickson, 2010). Numerous experts gained the opportunity to be a part of event industry, and the field of event management developed both in theory and practice. Event management can be defined as the design and the coordination of an event which includes research, planning, organizing, implementation, control and evaluation process (Moisce, Georgescu and Zgură, 2012). This complex process involves numerous experts, not only from the tourism sector, but also from many other sectors within, but also out of the destination. Event management process begins with the idea of staging an event and lasts after the event is over and evaluated. Beside the activities and offer within the certain event, there is a large number of elements in the destination which affect visitor satisfaction, such as destination attractiveness, quality and price of the accommodation, restaurants, attractions, shops, etc. These elements have to be included in all phases of the event management, especially in the research part, due to the fact that different groups of tourism demand have different needs due to mentioned elements. For instance, younger visitors of electronic music festivals will probably prefer cheaper accommodation and food. Therefore, these elements were included in the primary research and the results are shown later in the paper.

As Bowdin et al. (2011:25) stated "events do not take place in a vacuum - they touch almost every aspect of our lives, whether the social, cultural, economic, environmental or political". Due to the same authors, numerous benefits which arise from hosting an event are one of the main reasons for events popularity and support. Benefits (or positive impacts), as well as negative impacts, can be divided into four main groups: economic, environmental and social (or socio-cultural) and political (Van der Wagen and White, 2010). Although economic impacts were in the main focus of the organizers and the researchers for many years, other groups of effects gained the deserved importance, especially in the last decade. Every event which takes place in a certain destination has negative ecological impact which should be minimized as much as possible to be sustainable in the long run. In order to achieve a sustainable event which is sensitive to the environment within which is situated, this goal should be incorporated in event management and an environmental consultant should be involved in the whole process (Tassiopoulos, 2005). Furthermore, beside ecological impacts, social impact assessment has to be a part of the process of research, planning and management of every event in order to improve social well-being (e.g. poverty reduction) (Tassiopoulos and Johnson, 2009). Due to all mentioned, it is quite clear that event management is very complex and has to involve many stakeholders in order to maximize positive effect, and, at the same time, minimize negative effect of the event for the destination. One of the important elements for successful event management is incorporation of trends in event organization. The most important global trends in the event industry include: a) focus on sustainability; b) increased need for safety; c) unique venue experience; d) interactive entertainment; e) focus on diversity end inclusion; f) usage of wearable technology (Endless events, 2020). 
According to Goulding and Shanker (2011) electronic music festivals became one of the most successful forms of tourism for young adults, due to the fact that 1.5 billion people worldwide listens the electronic music (IMS Business Report 2019: 5). According to the same source, festivals saw the biggest annual increase from $18 \%$ in 2017 to $23 \%$ in 2018 within clubs and festivals with electronic music. Furthermore, fans of electronic music have a higher propensity to attend live music events (74\%) than those of any other genre.

To assure this growth in the long run, organizers have to explore recent trends on the demand side and include them in the process of managing the electronic music festivals. Beside previously mentioned trends in event industry, main market trends which should be considered when organizing music festivals include: a) more choices and more personalized experiences consumers want to enjoying greater choice and variety in everything from food to travel to on-demand entertainment; b) hybrid festivals attract bigger audiences and bring in more revenue - beside the primary theme of the festival, organizers should incorporate complementary lifestyle vendors and attractions such as craft beer, wine and spirits, exotic cars, food, and live music; c) online ticketing and more payment methods; d) usage of RFID technology and smart cards add value once inside the event - e.g. wristbands and prepaid smart cards: e) increasing role of social media - e.g. Instagram is amplifying word of mouth (Evenbrite, 2019). Organizers of electronic music festivals should incorporate these trends in their events in order to achieve competitive advantage.

Due to all mentioned, increase in the demand led to the increase in the supply, which resulted with the higher number of electronic music festivals. According to the web site Electronic music festivals, in 2020, 38 electronic music festivals were planned to be in Croatia, with almost 400,000 people attending. More than $50 \%$ with between 5,000 and 10,000 visitors, $24 \%$ with less than 5,000, while $21 \%$ with more than 10,000 visitors. Some of them were cancelled because of Covid 19 pandemic. The most visited one, Ultra Music Festival - Europe, usually has more than 150,000 visitors. It is also interesting that the majority (70\%) of electronic music festivals in Croatia takes place in July and August. Due to the results of Tomas research (IZTZG, 2020), 5.5\% of the examinees vas motivated to come to Croatia for having fun and visiting festivals, which places this motive among the 10 most important ones. Although the positive economic effects of electronic music festivals in Croatia are irrefutable, possible negative effects for the destinations has to be considered and minimized. For instance, Ultra Music Festival - Europe, as the biggest one, has negative ecological and socio-cultural effects such as: abasement of the resources, ecological contamination, air pollution, noise, criminal, dissatisfaction of locals, etc. These negative effects cannot be avoided, but can be minimized as much as possible. Some of possible solutions, such as organizing festivals in off season or in destinations with smaller number of tourists, are explained later in the paper. 
On the basis of all mentioned, it is possible to conclude that this market segment is constantly growing and represents a great potential for the destination and the organizers. However, this area is still under-researched, and needs to be segmented based on the demand characteristics.

Kotler (1980) suggested that the segmentation of the consumers should be based on one of four bases: demographic, geographic, psychographic and behavioural. Market segmentation is widely used to profile attendees (Tkaczynski and Rundle-Thiele, 2011: 426). Due to same authors, many event academics argued that "attendees should be segmented based on their motivations". A motive is "an international factor that arouses, directs and integrates behaviour of people" (Iso-Ahola, 1980, 1982), and represents a starting point in the decision-making process (Crompton and McKay, 1997: 425).

Crompton and McKay (1997: 426, 427) claim that "there are three main reasons for investing effort in better understanding the motives of festival visitors: (1) identification of visitors needs is a prerequisite for effectively developing elements of a festival and marketing them, (2) motives and expectations affect satisfaction and (3) identifying and prioritizing motives is a key ingredient in understanding visitor's decision processes".

According to Abreu-Novais and Arcodia (2013: 35,36), the majority of the event motivation research is based on one of three motivational theories. The first one is presented by Dann $(1977,1981)$. This theory includes push and pull factors, which means the internal motives and external forces. Second method is provided also by Dann (1977), but it is based only on push factors, due to the fact that person first experiences the internal need for travel. The third commonly used theory is "seek-escape dichotomy" provided by Iso-Ahola $(1980 ; 1982)$ which claims that "there are two main motivational forces: the desire to escape and the desire to seek intrinsic rewards". Furthermore, some of the research are based on Maslow's need hierarchy.

All mentioned theories are not created for event tourism motivation research and therefore cannot fully explain the behaviour of event tourists. The theoretical framework which is created for special event motives and behaviour is presented by Getz and Cheyne (2002) and includes three different dimensions of motivation: generic leisure and travel motives, extrinsic motives and event specific motives. This theoretical framework is commonly used in many event motivation research (e.g. Blešić et al., 2014; Vinnicombe and Sou, 2017; Riviera, Semrad and Croes, 2015; Kruger and Saayman, 2019; Kruger and Saayman, 2017), but the number of dimensions varies. Results of the existing research emergent several dominant dimensions which include: socialisation (can be divided in external and known group, cultural exploration, music, event novelty, escape, excitement and travel and relaxation). In 2001, Nicholson and Pearce noticed that the majority of the research involves individual events, while there is lack of more systematic and comprehensive approach of the event motivation. Nowadays, almost 20 years later, situation still remained quite 
same. Furthermore, researchers, as well as decision makers, have to be aware of the fact that motivation is very variable category, it is constantly changing due to numerous internal and external factors.

Due to prior studies and some specific features of electronic music festivals, and for the purpose of primary research, authors created highly structured questionnaire. The main aim is to understand the electronic music festival perception and motivation, as well as to identify the important dimensions of electronic music festivals from the potential visitors' point of view, in order to provide valuable data both for the scientists and practitioners.

\section{Methodology and research results}

In order to understand the electronic music festival perception and motivation, primary research was taken. Research instrument used in the paper is a structured online questionnaire. The questionnaire consists of four sections. First section includes general information on respondents. Second section examines the level of importance of 12 motives on the five-point Likert scale (1 - unimportant, 5 - very important), while third section examines the importance of chosen elements in destination. In the last section, respondents graded four electronic music components on the fivepoint Likert scale. Survey was distributed and collected in March 2020 among student population, due to the fact that they represent the important demand potential for electronic music festivals. Research sample included students from the University of Zagreb. Link on the questionnaire was distributed via teaching platforms. In total, 350 questionnaires were collected. When it comes to respondents' profile, the sample included 248 (70.9\%) females and 102 (29.1\%) males, while the average age was 21. The research included not only students who have already attended electronic music festival (effective demand), but also the potential one, in order to examine the potential differences between these two groups of demand. The majority of respondents belongs to the potential demand (70.9\%), while 102 respondents (29.1\%) has already attended electronic music festival.

For the data analyses, authors used descriptive statistics and factor analyses. Chosen techniques appertain to most commonly used techniques in the researched area (Tkaczynski and Rundle-Thiele, 2011). Questionnaire was created in Google forms, data were captured by using Microsoft Excel and analysed by using SAS.

Exploratory factor analysis, a method of multivariate analysis which "among the given variables defines those that best describe what they refer to" (Hair, Black, Babin, Anderson, 2010), included 12 motives. Examined motives were created on the basis of previous research on festival motivation (Kruger and Saayman, 2019; Vinnicombe and Sou, 2017; Blešić et al., 2014; Abreu-Novais and Arcodia, 2013; Crompton and McKay, 1997). “The Kaiser-Meyer-Olkin (KMO) measure of sampling adequacy 
statistic indicates whether the correlations between variables can be explained by the other variables in the data set" (Sarstedt and Mooi, 2014). The value of the KMO coefficient is 0.869 , which confirms that the data from the sample are appropriate for factor analysis, since "any value of the KMO coefficient higher than 0.5 is considered appropriate" (Williams, Brown, Onsman, 2010: 6). For the factor matrix rotation Varimax rotation was performed. "The factor loading of each item included in the analysis should be at least 0.5 , but lower loadings of above 0.3 can be accepted" (Sarstedt and Mooi, 2014). Table 1 represents the results of Varimax rotation.

Table 1: Results of Factor analyses

\begin{tabular}{|c|c|c|c|}
\hline \multicolumn{4}{|l|}{ Rotated Factor Pattern } \\
\hline & Factor1 - Music and fun & Factor2 - Travel & Factor3 - Socialization \\
\hline To enjoy live performances & 0.69219 & & \\
\hline To listen certain music genre & 0.65439 & & \\
\hline To enjoy main performers show & 0.65399 & & \\
\hline To enjoy the atmosphere & 0.57722 & & \\
\hline To enjoy dancing & 0.50254 & & \\
\hline To enjoy traveling & & 0.76690 & \\
\hline To meet the destination & & 0.75119 & \\
\hline To meet new people & & & 0.74327 \\
\hline To spend time with friends & & & 0.72774 \\
\hline Eigenvalue & 3.972 & 1.828 & 1.276 \\
\hline Variance $(\%)$ & 28.2 & 17.8 & 10.2 \\
\hline Cumulative variance $(\%)$ & 28.2 & 46 & 56.2 \\
\hline Reliability coefficient & 0.71 & 0.75 & 0.72 \\
\hline
\end{tabular}

After the analyses, three motives were excluded (to escape from everyday life, to spend time with people from foreign countries, to enjoy alcohol). These motives also have quite low mean average. Analyses resulted with three factors (music and fun, travel and socialization). In exploratory studies, acceptable value of Cronbach's alpha is 0.6 (Cronbach, 1951), which leads to conclusion that all three factors have high reliability coefficients. Cronbach's alpha reliability coefficient for the first factor (music and fun) is 0.71 , for the second factor (travel) is 0.75 and for the factor "socialization" is 0.72 . Therefore, it is possible to conclude that statements included properly describe the variable. Furthermore, it is possible to conclude that there is a high correlation between statements (all factor loadings are higher than 0.5). 
Table 2: Mean ratings and standard deviations of the items

\begin{tabular}{|l|c|c|}
\hline & Mean & $\begin{array}{c}\text { Standard } \\
\text { deviation }\end{array}$ \\
\hline To enjoy live performances & 3,86 & 1,20 \\
\hline To listen certain music genre & 3,85 & 1,24 \\
\hline To enjoy main performers show & 3,83 & 1,16 \\
\hline To enjoy the atmosphere & 3,80 & 1,19 \\
\hline To enjoy dancing & 3,79 & 1,22 \\
\hline To enjoy traveling & 3,76 & 1,22 \\
\hline To meet the destination & 3,51 & 1,21 \\
\hline To meet new people & 3,27 & 1,20 \\
\hline To spend time with friends & 3,14 & 1,14 \\
\hline
\end{tabular}

Table 2 shows that live performances are the most important motive among examinees (3.86), together with the travelling (3.85) and meeting the destination (3.83) which shows the importance of the destination where electronic music festival takes place. Meeting new people has the lowest mean value (3.14).

Table 3: Mean ratings of important elements

\begin{tabular}{|l|c|}
\hline Element & Mean \\
\hline Ticket price & 4.13 \\
\hline Price of accommodation & 4.11 \\
\hline Time period & 4.09 \\
\hline Other content on festival (food, drink, etc.) & 3.94 \\
\hline Destination attractiveness & 3.84 \\
\hline Other activities in destination (health, culture, etc.) & 3.77 \\
\hline Quality of accommodation & 3.52 \\
\hline
\end{tabular}

Third section of the questionnaire involved different elements in destination. As shown in the Table 3, all elements are quite important, since the lowest graded element (quality of accommodation) is graded with 3.52. The most important elements involve prices (ticket price and accommodation price) which is expected due to the fact that sample includes student population.

The last part of the questionnaire involved four electronic music components. Three of them were graded with high marks (energy $(4,32)$, music $(4,24)$ and production $(4,23))$, while text is not so important for electronic music fans.

On the basis of previous research and provided primary research results, hereafter authors will provide and discuss several recommendations for the improvement of electronic music festival offer and suggest the direction and possibilities for the future research of the area. 


\section{Discussion and conclusion}

As expected, motives with the highest mean value are closely related with the core of electronic music festival offer, the music itself. It includes live performances, main performers and the genre. This is the reason why organizers have to have at least one well established and well known performer on the festival. Famous performers can be attracted not only with the financial aspect, but also with the destination, credibility and tradition of the festival, previous experience and recommendations of his colleagues. A large number of famous performers loves to come and perform in Croatia, which provides further potential for electronic music festivals. When it comes to interrelation between dance and electronic music festival, previous research, as well our research, showed that dancing belongs to one of the main motives for attending electronic music festivals. High mean value for this motive in the majority of research can be explained by the fact that "electronic dance music could be described as music that has been produced with the foremost aim to make people move (dance)" (Burger and Toiviainen, 2018:187). This is one of the reasons (together with the constant increase of the songs and fans of EDM) for the increase in the demand and the number of electronic music festivals, especially in the last decade. Furthermore, Sloboda, O'Neill and Ivaldi (2001) explained why people love to be engaged with music. This engagement is enmeshed in a social and cultural world where people can "forget" the grounds on which their feelings and behaviours are based. Traveling for music deepens this feeling, due to the fact that people change their environment.

Despite the importance of motives which belong to the core of the event, research provided by Gelder and Robinson confirmed the thesis that multiple motivations is very important and that it can be very risky festival managers to rely only on the theme of the event. This is confirmed in our research, due to the fact that other motives also have high mean value, and cannot be neglected, such as traveling and meeting the destination. High mean value for this motives conferred the presumption that destination in which electronic music festival takes place is very important. Destination has to be attractive, but not necessarily well known. There are some festivals which take place always in the same destination, while there is well established festival which take place in different destinations, or in more than one destination. This kind of festivals provide an opportunity for some attractive, but quite unknown destination to become popular and to promote its offer. However, destinations have to be careful when hosting this kind of event, due to the fact that there is a large number of people who are quite noisy, which can affect other tourists' satisfaction in a negative way. This is a challenge which has several solutions. First one is to organize festival on "off season" if it is organized in established destination. Croatia has a problem with high seasonality. The majority of tourist arrivals and overnight stays takes place in July and September. To avoid possible dissatisfaction and conflicts, festival managers should thing about organizing festivals in June or September, which 
is now not the case. This would not only decrease seasonality, but also enable lower price of accommodation, which was, as shown in the Table 3, one the most important elements for the potential demand. The most important element was the ticket price, which could also be lower if the cost of the organization were lower, which is possible in off season. Second solution for the offer improvement is organizing festivals in the surrounding of famous destinations in peak season, with good connection with the famous destination. There are less developed and not well known destinations in Croatia which could host festivals. This solution is already implemented for several festivals, and has shown quite good results. These festivals have the continuity and become more and more recognized, providing many positive effect for the destination. Third possible solution is organizing more festivals in continental part of Croatia, which in, when it comes to tourism, quite underdeveloped. Organizing electronic music festival in continental Croatia, especially in rural areas, is quite challenging but has many positive sides. First one is the cost. The majority of services provided are cheaper, which will result with lower price and better offer. The key factor in this solution is good promotion. All three solutions, which have both positive and negative sides, could provide good results and be sustainable in the long run.

In order to assure sustainability and improve positive impact for the destination, festival managers should include some of the trends mentioned earlier in the paper. For instance, it is possible to include sightseeing of the destination or visit to main attractions in the ticket price, or provide coupons with the discount for restaurants, bars, attractions or excursions. This would not only provide economic benefits, but would also assure positive social impact for the local community and promote the destination offer.

In future research of electronic music festivals, motivation should be in the main focus, due to the fact that, as Pearce stated (2005:86), "study of motivations is fundamental and basic to the study of tourism development". According to Pegg and Patterson (2010) motivation is a key factor underlying all tourist behaviour. Although the motivation related research is in constant growth, the majority of search in the area is focused on one festival. Research should be broadened to larger number of festivals, in order to provide results which could be generalized and used in destination planning. Furthermore, future research should be more focused on potential demand (including younger generations), due to the fact that they represent the demand for festivals which will take place in the future, and that their mind set, behaviour and habits are quite different, due to the differences between generations (X, Y and Z).

It is possible to assume that constant changes (new songs, genres and performers), will lead to increase in electronic music festival demand, which will result with the increase of the quality and quantity of electronic music festivals worldwide. Croatia has potential to be more recognized destination in this area, but it has to be constantly engaged with the world trends. Furthermore, electronic music festivals should become a part of tourism development strategy and involve many stakeholders in the 
destination in order to be sustainable and accepted by the local community as well as compatible with all other forms of tourism in certain area.

\section{REFERENCES}

Abreu-Novais, M. \& Arcodia, C. (2013). Music festival motivators for attendance: Developing an agenda for research. International Journal of Event Management Research. 8(1), 34-48.

Agarwal, S., Busby, G. \& Huang, R. (2018). Special Interest Tourism: Concepts, Contexts and Cases. Oxfordshire: CABI.

Blešić, I., Pivac, T., Stamenković, I., Besermenji, S. \& Marković, S. (2014). Investigation of Visitor Motivation of The Exit Music Festival (The Republic of Serbia). Journal of tourism - studies and research in tourism. 18, 8-15.

Bowdin, G. A. J., Allen, J., O’Toole, W., \& McDonnell, I. (2011). Events management. Oxford: Elsevier Butterworth-Heinemann.

Burger, B. \& Tovianen, P. (2018). Embodiment in Electronic Dance Music: Effects of musical content and structure on body movement. Musicae Scientiae. 24(2), 186-205. DOI: $10.1177 / 1029864918792594$.

Caparrini, A., Arroyo, J., Pérez-Molina, L. \& Sánchez-Hernández, J. (2020). Automatic subgenre classification in an electronic dance music taxonomy. Journal of New Music Research. Retrieved June 15, 2020, from Taylor Frances online database on the World Wide Web: https://www. tandfonline.com/doi/full/10.1080/09298215.2020.1761399?scroll=top\&needAccess=true. DOI: $10.1080 / 09298215.2020 .1761399$

Crompton, J. L. \& McKay, S. L. (1997). Motives of visitors attending festival events. Annals of Tourism Research. 24(2), 425-439. DOI: 10.1016/S0160-7383(97)80010-2

Cronbach, L.J. (1951). Coefficient alpha and the internal structure of tests. Psychometrika. 16(3), 297334. DOI: 10.1007/BF02310555

Dann, G. M. S. (1977). Anomie, ego-enhancement and tourism. Annals of Tourism Research. 4(4), 184194. DOI: $10.1016 / 0160-7383(77) 90037-8$

Dann, G. M. S. (1981). Tourist motivation an appraisal. Annals of Tourism Research. 8(2), 187-219. DOI: 10.1016/0160-7383(81)90082-7

Derrett, R. (2009). How festivals nurture resilience in regional communities. In Ali-Knight, J., Robertson, M., Fyall, A. \& Ladkin, A. (Eds.) International Perspectives of Festivals and Events. Paradigms and Analysis. London: Routledge.

Douglas, N., Douglas, N. \& Derett, R. (2002). Special Interest Tourism. New York: Wiley.

Electronic festivals. Retrieved March 15, 2020 from: https://www.electronic-festivals.com

Endless events (2020). 2020 Event Trends - How Will the Industry Evolve? Retrieved September 29, 2020 from: https://helloendless.com/2020-event-trends/

Eventbrite (2019). New Trends Impacting Festival and Consumer Events. Retrieved September 29, 2020 from: https://www.eventbrite.com/

Frey, B. S. (1994). The economics of music festivals. Journal of Cultural Economics. 18(1), 29-39. DOI: 10.1007/BF01207151

Gelder, G. \& Robinson, P. (2009). A Critical Comparative Study of Visitor Motivations for Attending Music Festivals: A Case Study of Glastonbury and V Festival. Event Management. 13(3), 181196. DOI: $10.3727 / 152599509790029792$

Getz, D. \& Page, S. J. (2016). Progress and prospects for event tourism research. Tourism Management. 52, 593-631. DOI: 10.1016/j.tourman.2015.03.007 
Getz, D. (1989). Special events: defining the product. Tourism Management. 10(2), 135-137. DOI: 10.1016/0261-5177(89)90053-8

Getz, D. (2008). Event tourism: Definition, evolution, and research. Tourism Management. 29, 403428. DOI: 10.1016/j.tourman.2007.07.017

Goulding, C., \& Shankar, A. (2011). Club culture, neotribalism and ritualised behaviour. Annals of Tourism Research. 38(4), 1435-1453. DOI: 10.1016/j.annals.2011.03.013

Hair, J. F., Black, W. C., Babin, B. J., Anderson, R. E. (2010). Multivariate Data Analysis: A Global Perspective. New Yersey: Pearson.

Iso-Ahola, S. E. (1980). The Social Psychology of Leisure and Recreation. Dubuque IA: Wm. C. Brown.

Iso-Ahola, S. E. (1982). Towards a Social Psychology Theory of Tourism Motivation: A Rejoinder. Annals of Tourism Research. 9(2), 256-262. DOI: 10.1016/0160-7383(82)90049-4

IZTZG (2020). Tomas Hrvatska 2019. Stavovi i potrošnja turista u Hrvatskoj. Zagreb:IZTZG.

Kotler, P. (1980). Principles of Marketing. Englewood Cliffs, New Jersey: Prentice-Hall.

Kruger, M. \& Saayman, M. (2017). Segmenting beyond behavioural intentions: Fine tuning music festival visitors' music appreciation. International Journal of Event and Festival Management. 8(2), 204-223. DOI: 10.1108/IJEFM-09-2016-0064

Kruger, M. \& Saayman, M. (2019). 'All that jazz': the relationship between music festival visitors' motives and behavioural intentions. Current Issues in Tourism. 22(19), 2399-2414. DOI: $10.1080 / 13683500.2018 .1451496$

Moisce, D., Georgescu, B. \& Zgură, D. (2012). The use of event marketing management strategies. Procedia - Social and Behavioral Sciences 46, 5409 - 5413. DOI: 10.1016/j.sbspro.2012.06.448

Nicholson, R.E. \& Pearce, D.G. (2001). Why Do People Attend Events: A Comparative Analysis of Visitor Motivations at Four South Island Events. Journal of Travel Research. 39(4), 449-460. DOI: $10.1177 / 004728750103900412$

Novelli, M., (2005). Niche tourism: contemporary issues, trends and cases. Oxford: Elsevier Butterworth-Heinemann.

Pearce, P. (2005). Tourist Behaviour: Themes and Conceptual Schemes. Toronto: Channel View Publications.

Pegg, S. \& Patterson, I. (2010). Rethinking Music Festivals as a Staged Event: Gaining Insights from Understanding Visitor Motivations and the Experiences They Seek. Journal of Convention \& Event Tourism. 11(2), 85-99. DOI: 10.1080/15470141003758035

Riviera, M., Semrad, K. \& Croes, R. (2015). The five E's in festival experience in the context of Gen Y: evidence from a small island destination. Revista española de investigación de marketing. 19(2), 95-106. DOI: 10.1016/j.reimke.2015.06.001

Robinson, P. Wale, D. \& Dickson, G. (2010). Events Management. Oxfordshire: CABI.

Sarstedt, M. \& Mooi, E. (2014). A Concise Guide to Market Research: The Process, Data, and Methods Using IBM SPSS Statistics. Berlin and Heidelberg: Springer.

Shone, A. \& Parry, B. (2013). Successful Event Management: A Practical Handbook. Hampshire: Cengage Learning.

Sloboda, J.A. O’Neill, S.A. \& Ivaldi, A. (2001). Functions of Music in Everyday Life: An Exploratory Study Using the Experience Sampling Method. Musicae Scientiae. 5(1), 9-32. DOI: 10.1177/102986490100500102

St John, G. (2006). Electronic Dance Music Culture and Religion: An Overview. Culture and Religion. 7(1), 1-25. DOI: 10.1080/01438300600625259

Tassiopoulos, D. \& Johnson, D. (2009). Social impacts of events. In Raj, R. \& Musgrave, J., (Eds) Event Management and Sustainability (pp. 76-89). Oxfordshire: CABI.

Tassiopoulos, D. (2005). Event Management: A Professional and Developmental Approach Lansdowne: Juta and Company Ltd. 
Tkaczynski and Rundle-Thiele (2011). Event segmentation: A review and research agenda. Tourism management. 32(2), 426-434. DOI: 10.1016/j.tourman.2010.03.010

Van der Wagen, L. \& White, L. (2010). Events management for tourism, cultural, business and sporting events. Frenchs forest: Pearson.

Vinnicombe, T. \& Sou, P. U. J. (2017). Socialization or genre appreciation: the motives of music festival participants. International Journal of Event and Festival Management. 8(1), 274-291. DOI: 10.1108/IJEFM-05-2016-0034

Watson, K. (2020). IMS Business Report 2019: An annual study of the electronic music industry. Ibiza: IMS.

Weiler, B. \& Hall, C. M. (1992). Special Interest Tourism. New York: Halsted Press.

Williams, B., Brown, T. \& Onsman, A. (2010). Exploratory Factor Analysis: A five-step guide for novices. Australasian Journal of Paramedicine. 8(3), 1-14. DOI: 10.33151/ajp.8.3.93

Yolal, M., Çetinel, F. \& Uysal, M. (2009). An Examination of Festival Motivation and Perceived Benefits Relationship: Eskişehir International Festival. Journal of Convention \& Event Tourism. 10(4), 276-291. DOI: 10.1080/15470140903372020 